\title{
La sinagoga medieval de Molina de Aragón: evidencia documental y epigráfica
}

Jesús A. Arenas Esteban, Universidad a Distancia de Madrid Javier Castaño, ILC - CCHS, CSIC ${ }^{*}$

\footnotetext{
Noticias acerca de la sinagoga de Molina de Aragón (Guadalajara) y análisis de los fragmentos epigráficos hebreos aparecidos durante las excavaciones realizadas en el yacimiento arqueológico de «Castil de Judíos» de dicha localidad y cuyos restos hallados corresponderían al siglo XIV.

Palabras ClAVE: arqueología medieval; sinagoga; Castilla; epigrafía hebrea; cultura material.

The Medieval Synagogue of Molina de Aragon: Documentary and Epigraphic Evidence.Information concerning the $14^{\text {th }}$ century synagogue of Molina de Aragon (Guadalajara), with an analysis of the Hebrew epigraphic fragments found during the excavations made in the arqueological site of "Castil de Judíos."
}

KeYwords: Medieval Archaeology; Synagogue; Castile; Hebrew Epigraphy; Material Culture.

La aljama judía de Molina de Aragón, en el extremo oriental de la antigua Corona de Castilla, tuvo cierta relevancia en el conjunto de la judería castellana durante los siglos XIII y XIV. Estrechamente relacionada con las aljamas de Cuenca -a 88 km de distancia-, y Daroca (en Aragón) -a 50 km-, dichas comunidades mantuvieron una intensa interacción humana durante los siglos bajomedievales, muestra temprana de la cual es R. Yonatán b. Ya'aqob, un talmudista nacido en la primera mitad del siglo XIII en Molina y que se traslada a Cuenca ${ }^{1}$. Durante el siglo XIV, indicios onomásticos adicionales apuntan en la misma dirección ${ }^{2}$.

* jesusalberto.arenas@udima.es; javier.castano@cchs.csic.es

${ }^{1}$ B. Septimus, «'Kings, Angels or Beggars': Tax Law and Spirituality in a Hispano-Jewish Responsum», en I. Twersky (ed.), Studies in Medieval Jewish History and Literature. Vol. I (Cambridge, MA 1984), págs. 309-335.

${ }^{2}$ Es significativo que de los diez judíos que en 1326 firman una avenencia relativa al crédito entre la aljama y el concejo de Cuenca, tres de ellos lleven el nombre de familia «de Molina», cf. F. A. Chacón Gómez (ed.), Colección Diplomática del Concejo de Cuenca. 1140-1417 (Cuenca 1998), doc. 53. 
Hasta, al menos, finales del siglo XIII, la villa de Molina dispone de cierta autonomía política respecto al poder real. Aunque a la postre integrada en la Corona de Castilla, su localización fronteriza, junto a otros factores, explica su situación entre 1369 y 1375 bajo dominio del rey de Aragón. De estos años se conserva una rica documentación en relación a determinados aspectos de la aljama en la villa, y acerca de la ascendencia social de la familia Abolafia ${ }^{3}$. No conocemos datos acerca de los efectos de la violencia de 1391, pero es muy posible que al igual que ocurre en Cuenca, la aljama de Molina sufriera graves trastornos.

La información disponible sobre los judíos para el siglo XV es aún más escasa. Se registra la presencia de judíos en la villa, aunque la aljama como tal desaparece bruscamente tras la conversión y el abandono de algunos judíos en busca de otros horizontes ${ }^{4}$, reduciéndose a la presencia temporal, al menos, desde mediados de siglo, de algunos individuos.

\section{La sinagoga de «Castil de Judíos»: evidencia documental y registro arqueológico}

Un estudioso señalaba que «the history of every synagogue is [...] to a certain extent the history of the community» ${ }^{5}$. Sin embargo, son escasas las referencias documentales conservadas relativas a la sinagoga de Molina, y todas ellas datan de fines del siglo XV, un periodo en el que el edificio había sido ya abandonado.

De hecho, un proceso inquisitorial recogía un testimonio acerca de Juan Fernández Gresón, que «yva cada mañana a Castil de Judíos, que fue antiguamente synoga de judíos, e que non sabe este testigo lo que allí se hazía» ${ }^{6}$. Otros testimonios nos informan que el barrio circundante seguía todavía habitado. Así,

${ }^{3}$ L. Benítez Martín. Documentos para la Historia de Molina en la Corona de Aragón: 13691375 (El registro 1551 de la Cancillería de Pedro IV) (Zaragoza 1992).

${ }^{4}$ Un caso es el de Samuel Abenaya, un prestador judío de Molina desplazado temporalmente a Aragón que el 28-IX-1412 acusaba a tres vecinos de Calatayud y de aldeas de Daroca de haberle robado e intentado matar, cf. Regesta of Documents from the Archivo de la Corona de Aragón. Fernando I. 1412-1416. The Tortosa Disputation, comp. G. EsCRIBÀ I Bonastre (Jerusalem 1998), doc. 24. El mismo día, el rey de Aragón ordenaba a los oficiales la detención de los agresores, concediendo guiaje y protección especial en tierras aragonesas a Samuel, a su padre y a dos hermanos (ibíd. doc. 25; y cf. también doc. 34 y 47).

${ }^{5}$ Y. T. Assis, «Synagogues in Medieval Spain», Jewish Art 18 (1992), págs. 7-29: 8.

${ }^{6}$ E. Cantera Montenegro, «Solemnidades, ritos y costumbres de los judaizantes de Molina de Aragón a fines de la Edad Media», en II Congreso Internacional «Encuentro de las Tres Culturas». Toledo, 3-6 de octubre de 1983 (Toledo 1985), págs. 59-88: 63. 
Juana Fernández la Brisela afirma en su confesión que «las [conversas] que bebían en el Castil de Judios venían cada sábado conpuestas a ver las de abaxo» ${ }^{7}$. Y Yoçé Pachel el viejo, un musulmán, dejaba implícito que hacia 1460 ya no había sinagoga en Molina donde celebrar las fiestas judías, porque los escasos judíos que entonces residían circunstancialmente en la villa, entre ellos Mosé Abén Xuxén, junto a varios conversos y su criado Ysaque, celebraban Kippur en casa de Juan Gallego ${ }^{8}$. Un último testimonio es el de Juan de la Puente, que declara haber visto a Pedro Bernal rezando oraciones de judíos, porque este testigo «de aquella manera lo vió hazer a unos judíos en la synoga de Medinaçeli», quizás porque ya no había oportunidad de ver algo similar en Molina?.

Estas magras referencias documentales a una sinagoga en el «Castil de Judíos» se han visto completadas con motivo de la excavación iniciada a fines de la última década y continuada a lo largo de sucesivas campañas, y que dejaron al descubierto restos de un asentamiento judío datado en el siglo XIV ${ }^{10}$. Especial relevancia tuvo en 2000 el hallazgo de un fragmento de yeso conteniendo tres letras hebreas y parte de un capitel junto a otras piezas de yesería ornamental, en el marco de un edificio que podría identificarse con dicha sinagoga.

El yacimiento arqueológico de «Castil de Judíos» se ubica en la cota más alta del actual núcleo urbano de Molina, junto a una de las entradas al albacar de la fortaleza medieval. La configuración urbanística excavada se concreta de manera más o menos definitiva a lo largo del siglo XIII, y es durante el XIV cuando puede caracterizarse una fase hispano-judía. Dentro del yacimiento excavado sobresale un edificio de planta rectangular, cuyas dimensiones son 9,80 x 16,40 m, y cuyos muros de cierre en los flancos sur y oeste desaparecieron a comienzos del siglo XIX (fig. 1).

La estructura analizada no es una edificación de entorno doméstico y tampoco un templo cristiano: posee testero plano sin ábsides, con un eje orientado norte-sur y pegado a la muralla de la villa. Su interior estuvo decorado con yeserías parietales de estilo «mudéjar», parte de cuyos motivos decorativos lo eran textos epigráficos en hebreo. Estas yeserías ornamentales formaron parte de decoración parietal de una sinagoga. Algunas ofrecen esquemas geométricos

${ }^{7}$ Cantera Montenegro, «Solemnidades, ritos y costumbres», pág. 65.

${ }^{8}$ Cantera Montenegro, «Solemnidades, ritos y costumbres», pág. 67.

${ }^{9}$ Cantera Montenegro, «Solemnidades, ritos y costumbres», pág. 72.

${ }^{10}$ Una visión de conjunto de los resultados de la excavación arqueológica en J. A. ARENAS Esteban, «El asentamiento del "Castil de Judíos", Molina de Aragón (Guadalajara)», en ¿Una Sefarad inventada? Problemas de interpretación de los restos materiales hispano-judíos (de próxima publicación). 


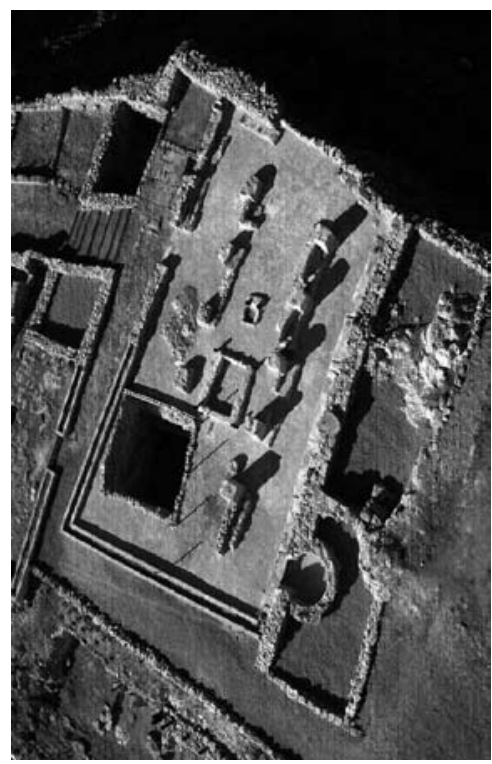

Fig. 1: Vista aérea de la planta excavada en el «Castil de Judíos»

y seudovegetales, y formaron parte de frisos y plafones parietales de gran formato, e incluso, de capiteles. Otras, muy escasas, contienen textos en hebreo.

Uno de los accesos al edificio, probablemente el principal, se produciría por el muro occidental, junto a un pequeño patio pavimentado con losas de piedra arenisca.

El espacio interior excavado aparece organizado en tres naves separadas por pilares rectangulares o cuadrados, y unos bancos de yeso ocupan los espacios entre los pilares, apareciendo también adosados a los muros; estos bancos no se han podido documentar en la nave occidental, pero sí en la central y el muro oriental. En la nave central sobresale una estructura rectangular de 2,10 x 1,30 m que estaba construída con muros de yeso elevados $35 \mathrm{~cm}$ sobre el pavimento. En sus cuatro esquinas conserva improntas de postes de madera, de 15 x $15 \mathrm{~cm}$ de sección, que indican la existencia en origen de una estructura de madera sobreelevada. Junto a ella, otra estructura más pequeña de yeso con dos improntas de pies derechos de madera, en cuya concavidad interior se hallaron restos de varios recipientes de vidrio, monedas de Fernando IV y Alfonso XI y un instrumento de bronce. Dicha estructura se sitúa frente a los únicos dos pilares de sección poligonal existentes en el edificio, a cuyos pies aparecieron restos de dos grandes capiteles (fig. 2). 


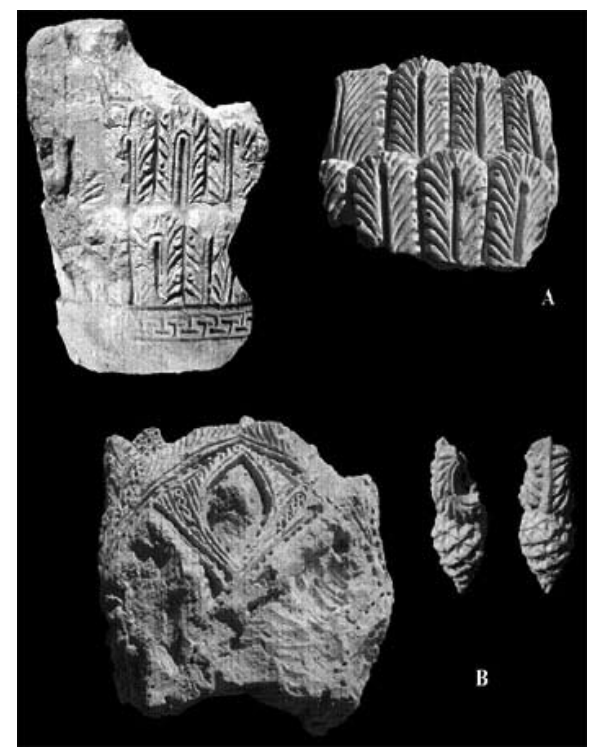

Fig. 2: Fragmentos de capitel con roleos hallados en el interior de la sinagoga de «Castil de Judíos». A) nave occidental y B) nave oriental

Interesante también resulta la presencia de un cubículo de planta circular de pequeñas dimensiones $-1,45 \mathrm{~m}$ de diámetro- abierto en el muro oriental del edificio. Su único acceso se encontraba sellado, primero por el banco corrido dispuesto a lo largo de todo ese muro y, segundo, por un tabique de yeso cuyos restos eran patentes hasta $0,70 \mathrm{~m}$, la cota más alta de muro conservada en ese punto. El interior de ese cubículo se encontró vacío por lo que es imposible establecer su función original.

En el subsuelo del edificio se ha documentado una cisterna de grandes dimensiones. Varios elementos permiten sostener que es de época anterior, posiblemente andalusí, quedando integrada en el edificio en el transcurso de su construcción. Este aljibe estaría cubierto con una bóveda de argamasa de medio punto cuyos arranques se encontraron perfectamente conservados. No obstante, y a pesar de que las abrasiones en la parte central del pavimento indican la primitiva existencia de un brocal en la parte superior, ha sido imposible reconocer cualquier tipo de acceso pedestre que pudiese indicar su reutilización para usos rituales.

Existen elementos para plantear que la construcción del edificio es anterior al siglo XIV. El más importante es su propia traza arquitectónica. Aunque por desgracia no disponemos de suficientes modelos de comparación, el hecho es que 
las sinagogas conservadas datadas en los siglos XIV y XV (la de Šemuel ha-Leví de Toledo, la de Córdoba, y los restos recientemente excavados en Lorca que podrían identificarse con los de una sinagoga) responden, independientemente de sus dimensiones, al esquema de una nave única diáfana. Por el contrario, el diseño basilical con el interior dividido en naves separadas por pilares documentado en Molina resulta más acorde con planteamientos constructivos característicos del siglo XIII y plasmados en casos como las sinagogas actualmente conocidas como Santa María la Blanca y Corpus Christi, de Toledo y Segovia, respectivamente.

Un aspecto importante es el de la datación del edificio. A este respecto, deberíamos empezar por la cronología, necesariamente aproximada, que aportan las yeserías parietales de diseño geométrico-vegetal (fig. 3); elemento que muestra marcadas similitudes con las conservadas en sinagogas como la de Cuenca" ${ }^{11}$ también la de Córdoba, esta última dedicada en 1314/15. Por el contrario, este diseño presenta marcadas diferencias con la decoración más exhuberante de la sinagoga de Šemuel ha-Leví de Toledo, de mediados de siglo XIV. Eso ayudaría a precisar el momento de instalación de las yeserías en el edificio de Molina, la primera mitad del siglo XIV, cronología refrendada por las emisiones monetales más modernas documentadas en el interior del edificio que, como ya se ha indicado, corresponden al reinado de Alfonso XI (1312-1350).
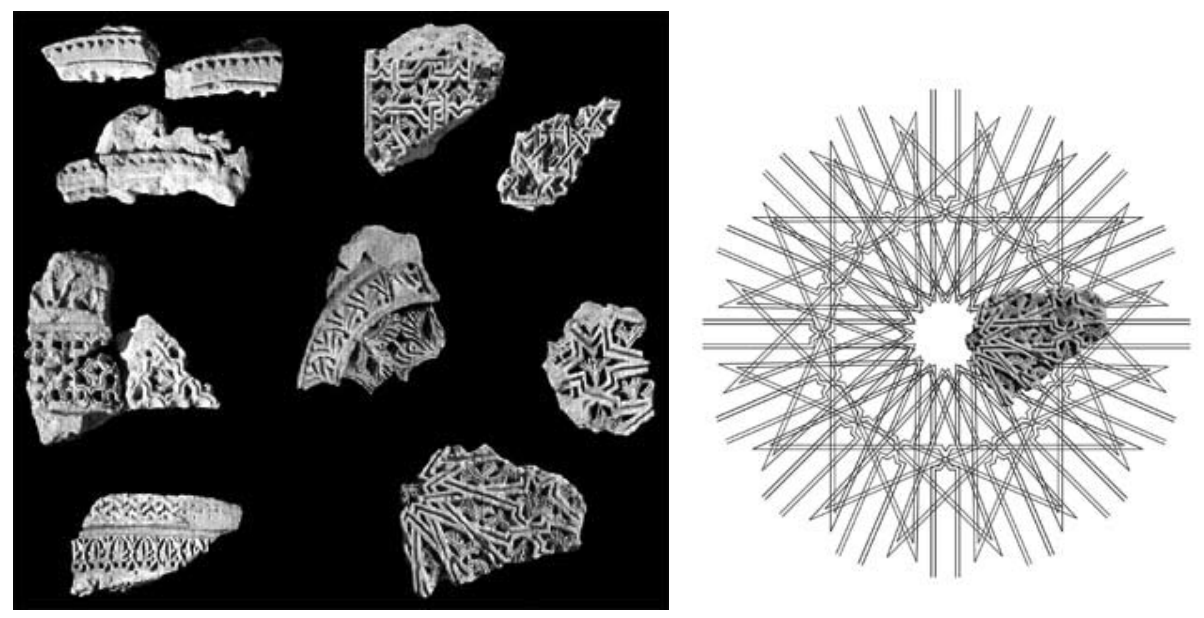

Fig. 3: Yeserías parietales aparecidas en el interior de la sinagoga de «Castil de Judíos». Lacería con detalle de panel decorativo y reconstrucción de diseño

${ }^{11}$ D. Pérez Ramírez, «La sinagoga de Cuenca, iglesia de Santa María la Nueva», Cuenca 1920 (1982), págs. 47-78: 73-77. 
Aparte de la morfología constructiva del edificio, y su localización destacada en el barrio de «Castil de judíos» o judería, un argumento de peso a la hora de identificar dicho edificio con una sinagoga son los restos de epigrafía hebrea hallada, y cuyo análisis ofrecemos más adelante ${ }^{12}$. No obstante, al intentar realizar dicha identificación se plantean algunos problemas de interpretación del edificio como son la determinación de la orientación de la estructura, la dificultad de localizar claramente un hejal -hornacina donde se depositan los rollos de la Torá- (no parece, quizás, factible localizarlo en el muro oriental donde corre una fila de asientos), y de las distintas puertas de acceso, entre ellas, la de las mujeres, si es que había un espacio a ellas reservado, además de la identificación de un atrio.

Un estudio reciente ha mostrado que las sinagogas medievales no tenían necesariamente por qué tener una orientación específica ${ }^{13}$. No ha sido posible localizar el hejal de la sinagoga de Molina, aunque es cierto que el muro meridional fue desmontado hace casi dos siglos. Otro de los rasgos distintivos de este edificio es su carácter exento por dos de sus lados, con un muro -el septentrionaladherido a la muralla de la villa, fenómeno repetido en sinagogas construidas en esos siglos y sobre el cual ha llamado la atención un reciente investigador ${ }^{14}$. Con unas dimensiones similares a la sinagoga de los Abencabra de Calatayud, la superficie interior -unos 160 metros cuadrados-permitiría la presencia de, al menos, medio centenar de personas sentadas.

Durante la campaña de 2002 se practicó un sondeo para analizar la estructura del subsuelo de la sinagoga, lo que proporcionó la oportunidad para documentar un relleno compuesto por tierra y, sobre todo, material constructivo amortizado en el que se pudo individualizar un lote de revestimientos parietales (fig. 4) de características totalmente diferentes a las de los documentados sobre el pavimento superior. Por un lado, destacan varios fragmentos de enlucido pintado al fresco con motivos lineales en negro sobre fondo rojo; por otra, también se recuperaron algunos restos de yeserías molduradas con un diseño mucho más sobrio que el de las de la última fase de la sinagoga y, además, recubiertas con pintura verde. Estos elementos, junto a la presencia de los aludidos capiteles decorados con piñas y roleos similares a los existentes en los edificios mencionados de To-

${ }^{12}$ Sigue siendo modélico el análisis realizado por F. SABATÉ I Curull, «En torno a la identificación de sinagogas medievales: el caso de Tárrega», Sef 59 (1999), págs. 127-158.

${ }^{13}$ J. Riera I SANS, Els poders pùblics i les sinagogues. Segles XIII-XV (Girona 2006), pág. 194.

${ }^{14}$ Según Riera i Sans, «sense que puguem dir que es compleix com si fos llei, la gran majoria de les sinagogues bastides als segles XIII i XIV toquen als murs de la vila», cf. Els poders pùblics i les sinagogues, pág. 189. 


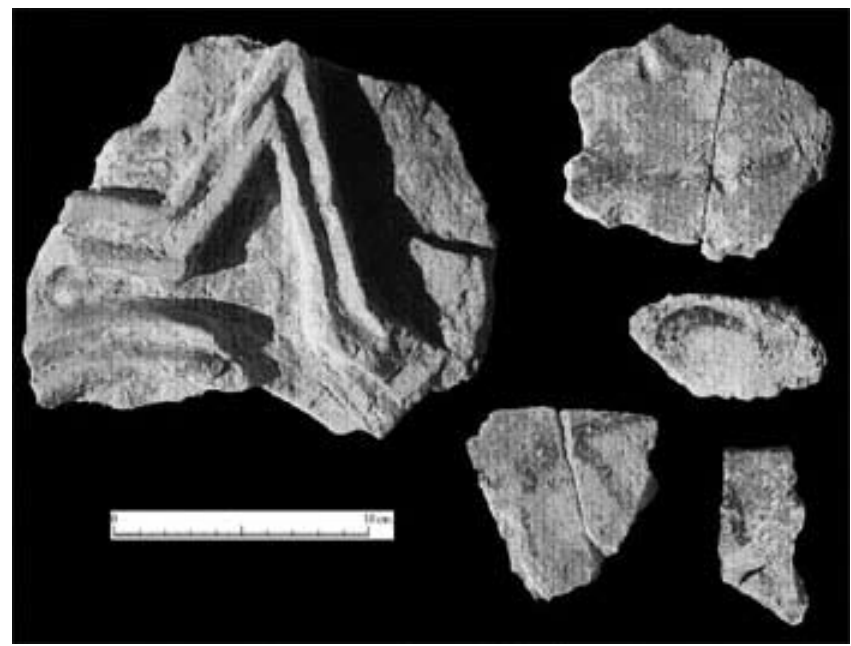

Fig. 4: Fragmentos de yesería aparecidos bajo el pavimento de la sinagoga de «Castil de Judíos»

ledo y Segovia, nos están indicando la existencia de un edificio de cierta calidad constructiva anterior a los restos datados en el siglo XIV.

En consecuencia, y aún a falta de cartelas fundacionales o cualquier otro tipo de texto orientativo, no es descabellado situar la construcción de la sinagoga de Molina en algún momento del siglo XIII, al que seguiría un proceso de mejoras y embellecimiento que aportó el aspecto que ostentaba el edificio hacia finales del siglo XIV. ¿Qué es lo que ocurre en torno a 1391? Aún no lo sabemos. Lo que sí parece claro es que, a diferencia de lo ocurrido en Cuenca, donde su sinagoga fue convertida en iglesia después de ese año, la de Molina de Aragón fue posiblemente abandonada.

\section{Evidencia epigráfica}

Las excavaciones arqueológicas han permitido recuperar fragmentos de epigrafía hebrea junto a otros simplemente decorativos de diversa tipología: capiteles, cenefas, celosías, un fragmento de arco, lacerías, roleos y frisos. A continuación presentamos una descripción de aquellos fragmentos que contienen texto hebreo. Los paneles de yeserías ornamentales con epigrafía aparecieron en el pasillo que comunicaría la estructura central -¿tebá? - con la pared oriental ${ }^{15}$.

${ }^{15}$ Ya se ha subrayado la centralidad de la tebá, una plataforma de madera, en la sinagoga de Šemuel ha-Leví, de Toledo, cf. F. Cantera Burgos, Sinagogas de Toledo, Segovia y Córdoba (Madrid 1973), pág. 102. Unos fragmentos de yesería carentes de contenido epigráfico y atribuidos 
Quince de las piezas epigráficas examinadas están depositadas en el Museo de Guadalajara, concretamente las más valiosas, junto a los fragmentos de capitel, mientras que otros cinco fragmentos de yeserías parietales con decoración geométrica están expuestos en el Museo de Molina. Los fragmentos con contenido epigráfico conservados son los siguientes:

1. Panel decorativo con inscripción del salmo 27:4, con restos de policromía. En este texto, Israel expresa (en primera persona) la confianza en Dios, y recuerda que había solicitado y pretende habitar en la Casa del Señor todos los días de su vida,

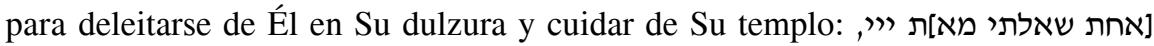
אותה אבקש [שבתי בבית "י כל ימי חיי] 'Una cosa he demandado a]l Señor, esta buscaré [que esté yo en la casa del Señor todos los días de mi vida]'). Aparecido en la campaña de 2001. El texto de este salmo fue utilizado también en el muro oriental de la sinagoga de Córdoba ${ }^{16}$.

2. Friso con decoración (fragmento), parte inferior (final de línea) de dos letras hebreas, quizás ה.....

3. Friso con decoración (fragmento): es posible que el texto hebreo hiciera referencia al salmo 67:2, donde se realiza una alabanza universal a Dios. Ese mismo salmo fue utilizado en la decoración del muro septentrional de la galería femenina de la sinagoga de Šemuel ha-Leví, de Toledo ${ }^{17}$ : [אלהים יחננו ויברכנו יאר פניו] אתנו [סלע] ('[Ten misericordia] de nosotros [Señor, y bendícenos, haz resplandecer Tu rostro sobre nosotros]') (fig. 5).

4. Inscripción (en tres fragmentos): מבוא, palabra que aparece en el texto bíblico en 14

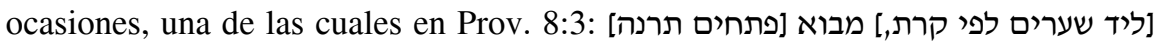
('En el lugar de las puertas, a la entrada de la ciudad, a la] entrada [de las puertas da voces']). El versículo 8:34 de Proverbios fue utilizado en la sinagoga de Córdoba, encuadrando la puerta del muro meridional ${ }^{18}$.

5. Inscripción (fragmento) árabe, donde se pueden identificar dos letras ال (alif, lam), bien como artículo, bien como comienzo de «Al-lá», a las que, quizás, precedería ¿waw? en posición perpendicular a las dos posteriores ('y Dios').

6. Inscripción (fragmento): כו (¿?)

7. Inscripción (fragmento) en dos líneas superpuestas: ובב I .......

a una sinagoga, han sido objeto de estudio en M. Pérez Asensio, F. Koch, E. Moreno León, P. SÁnchez GómEZ, «Las yeserías de la sinagoga del castillo de Lorca, Murcia», en Lorca. Luces de Sefarad (Murcia 2009), págs. 222-257.

${ }^{16}$ Cantera Burgos, Sinagogas de Toledo, Segovia y Córdoba, págs. 167-172.

${ }^{17}$ Cantera Burgos, Sinagogas de Toledo, Segovia y Córdoba, pág. 129.

${ }^{18}$ Cantera Burgos, Sinagogas de Toledo, Segovia y Córdoba, pág. 163. 
8. Inscripción (fragmento): שרר; si fuera de procedencia bíblica, quizás pudiera hacer referencia a Ester 1:22, להיות כל איש[ שרר [בביתו], ['que todo hombre] afirmase [su autoridad en su casa'], pero parece dudosa esta posibilidad. Una línea superior parece indicar que formaría parte de un friso con otra inscripción sobrepuesta.

9. Inscripción (fragmento): 2 '.

10. Inscripción (fragmento): בוא o quizás כוא.

11. Inscripción (fragmento): ilegible (מן?).

12. Inscripción (fragmento): quizás איש.

13. Inscripción (fragmento): ...

14. Inscripción (fragmento): ..า.

15. Inscripción, parte inferior de dos letras, la segunda de las cuales es álef (incompleta) (fig. 6).

Recibido: $17 / 11 / 2008$

Aceptado: 05/03/2010 (versión final) 

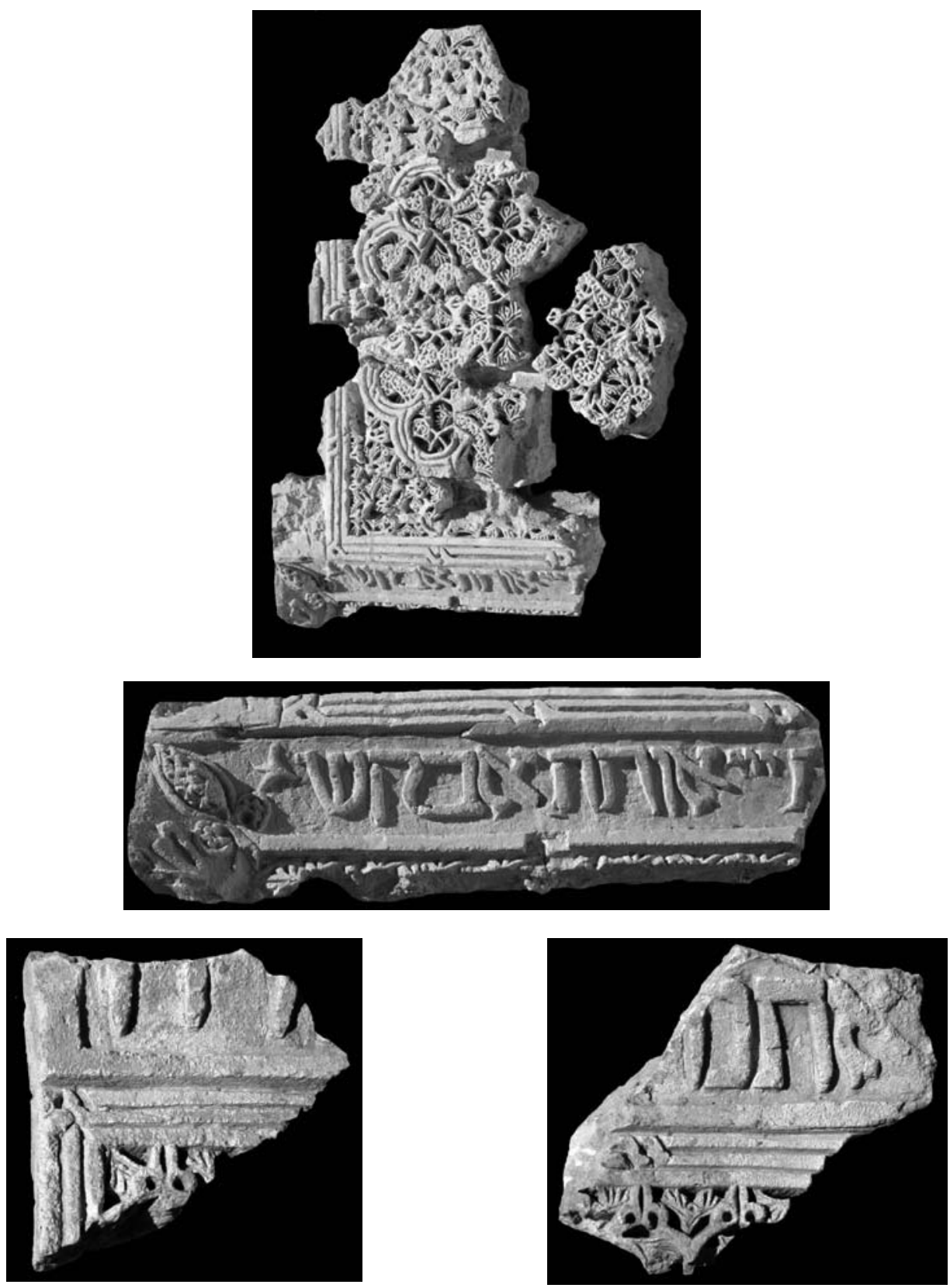

Fig. 5: Fragmentos (n. ${ }^{\circ} 1$ y detalle, 2, 3) de paneles decorativos con epigrafía hebrea. 

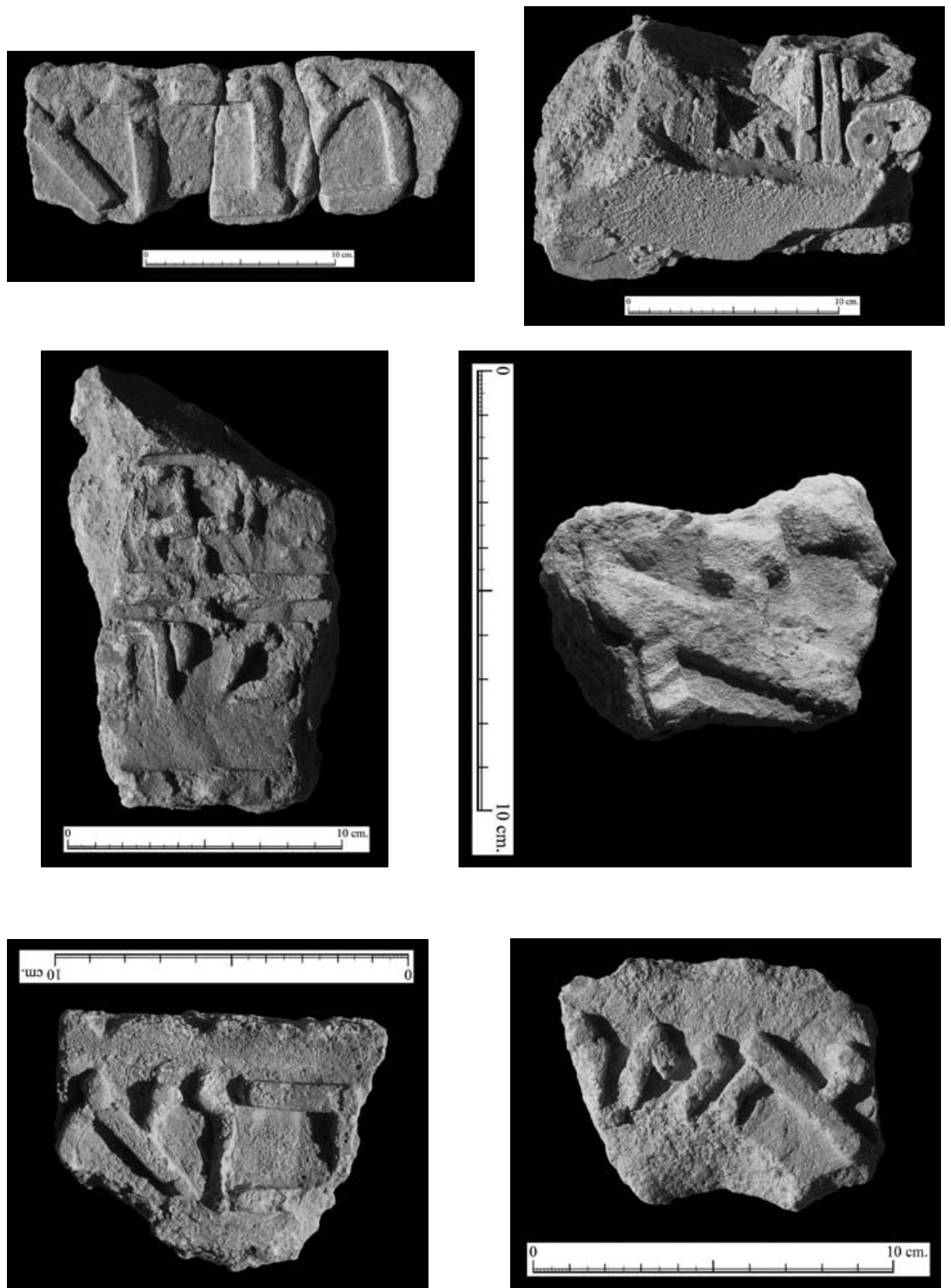

Fig. 6: Fragmentos $\left(\mathrm{n}^{\circ}\right.$ 4, 5, 7, 9, 10 y 12) de paneles decorativos con epigrafía hebrea (ordenados de izquierda a derecha, de arriba abajo). 